\title{
Transforming rice cultivation in flood prone coastal Odisha to ensure food and economic security
}

\author{
Manzoor H. Dar ${ }^{1} \cdot$ Ritadhi Chakravorty $^{2} \cdot$ Showkat A. Waza $^{1} \cdot$ Mayank Sharma $^{1}$ • \\ Najam W. Zaidi ${ }^{1}$ - Amrendra N. Singh ${ }^{1} \cdot$ Umesh S. Singh $^{1} \cdot$ Abdelbagi M. Ismail $^{3}$
}

Received: 19 November 2016 / Accepted: 30 May 2017 /Published online: 1 July 2017

(C) The Author(s) 2017. This article is an open access publication

\begin{abstract}
Flash floods leading to complete submergence of rice plants for 10-15 days is one of the major constraints for rice production, mainly in rainfed lowland areas. In India, $30 \%$ of the rice growing area (12-14 M ha) is prone to flash flooding with average productivity of only $0.5-0.8 \mathrm{t} \mathrm{ha}^{-1}$. Coastal Odisha is one of the most flood prone areas of India where the paddy crop in the wet season is often devastated by flash floods, forcing farmers either to discontinue paddy cultivation or to revert to traditional varieties with very low yields. The flood tolerant variety, Swarna-Sub1 (SS1), was introduced through cluster demonstrations in some villages of the Bari block of Odisha in 2013. SS1 seeds were provided to 355 farmers in two villages affected by floods twice in 2013. The majority of the farmers cultivated SS1 in 2013 and about $75 \%$ of them persisted with the variety in 2014 . There has been a steady and significant increase in paddy cultivation and yields per unit area between 2012 and 2014 and a sharp increase in paddy sales during 2013 and 2014. The present study showed that farmers preferred to cultivate low yielding traditional land races owing to their better flood tolerance and the unavailability of flood tolerant high yielding varieties (HYVs). Traditional varieties gave 30-42\% higher yields than non-SS1 HYVs when flooding occurred. SS1 on the other hand offered a significant yield advantage of about twice that of traditional varieties, in both flooding and non-
\end{abstract}

Manzoor H. Dar

m.dar@irri.org

1 International Rice Research Institute (IRRI-India), NASC Complex, New Delhi, India

2 University of California, Berkeley, CA, USA

3 International Rice Research Institute (IRRI), DAPO Box 7777, Metro Manila, Philippines flooding years. There is an additional social advantage of SSI in that famers belonging to scheduled castes in flood prone villages, have greater numbers of plots that are exposed to prolonged floods. Thus they benefit proportionately more from the introduction of SS1.

Keywords Flooding tolerance $\cdot$ Grain yield $\cdot$ High yielding rice varieties $\cdot$ Swarna-Sub1 $\cdot$ Traditional varieties

\section{Introduction}

Rice is a staple food for more than half of the world's 7 billion people. More than $90 \%$ of the global rice is produced and consumed in Asia. South Asia has about 37\% of the world's total rice area and approximately half of that is rainfed (Dawe et al. 2010). Flash floods leading to complete submergence of plants for 10-15 days is one of the major recurring problems for rice production in rainfed lowlands of South and SouthEast Asia (Septiningsih et al. 2009). In India 30\% of the rice growing area (12-14 $\mathrm{M} \mathrm{ha}$ ) is prone to flash flooding with average productivity of only $0.5-0.8 \mathrm{t} \mathrm{ha}^{-1}$ (Bhowmick et al. 2014). Coastal Odisha is one of the most flood prone areas of India where the paddy crop in the wet season is often devastated by flash floods, causing farmers either to discontinue paddy cultivation or revert to low-yielding traditional landraces. Thus, the recurrent floods reduce farmers' seasonal earnings, thereby affecting their inclination to experiment with the latest technologies, including planting new varieties (Dar et al. 2013).

Flash floods may completely submerge the plant, restricting gaseous exchange and thereby hindering growth processes leading to its decay and death. Most aerobic crops cannot withstand standing water or water logging but rice thrives in shallow standing water because it can maintain 
oxygen supplies to the root through its extensive aerenchyma. However, most of the rice cultivars cannot survive complete submergence for more than a week (Palada and Vergara 1972; Adkins et al. 1990). Thus, the extent of damage caused by flooding varies according to the depth and duration of submergence and is further conditional on the topography of the land (Mishra et al. 2010), and floodwater conditions (Das et al. 2009). The extent of loss during most flood incidences is severe and irreparable as the crops are generally in an active stage of growth with farmers already having made significant investments in terms of inputs. Furthermore, farmers lose the cultivation season in the aftermath of flooding, as the flooded land cannot be put to immediate use. Consequently as the majority of low and medium level land is under paddy cultivation during the wet season, farmers often sustain great losses, particularly when floods occur late in the season.

With the long-term adverse effects of climate change, the risk of farmers' exposure to extreme flood events is high. Many areas are expected to flood as a consequence of sea level rise, uneven distribution of rainfall, and predicted increases in the frequency and intensity of flooding caused by extreme weather events (Coumou and Rahmstorf 2012; Mackill et al. 2012). Incorporating stress tolerance into high yielding varieties has proved to be a most practicable approach for developing varieties that can cope with these situations (Ismail et al. 2013). This provides optimism that the problem of climate change can be addressed partially through the development of varieties adapted to the changing conditions and consequently capable of producing yields that are resilient.

Using marker assisted breeding (MAB), the International Rice Research Institute (IRRI) successfully incorporated the Sub1 (Submergence tolerance 1) Quantitative Trait Locus (QTL) from an Indian landrace to several popular rice varieties, including the mega variety Swarna, which is commonly grown in Odisha and many other states of India (Bailey et al. 2010; Tester and Langridge 2010; Singh et al. 2013). The new version of Swarna, called SS1, can withstand complete submergence for over two weeks and recover as flood water recedes. After a few years of evaluation and its excellent performance in farmers' fields, SS1 was released in India for commercial cultivation. Odisha, being the state with a prolonged history of floods has taken up the seed multiplication of this variety for the use of farmers in coastal districts where flooding is prevalent.

Agriculture is the mainstay of the majority of the population in rural Odisha and thus holds the key to the socioeconomic development of the state. Floods have been the most regular abiotic factor, with the entire $482 \mathrm{~km}$ coastal line of the state being exposed to frequent floods and water logging. Heavy rainfall along the hills of Odisha and floodwaters flowing in from the highland states of Jharkhand and Chhattisgarh also contribute to flooding along coastal lines and deltaic areas of the state. Apart from heavy rainfall, cyclonic winds and tidal flows also cause floods in coastal areas. Flash-flood water caused by heavy rains or outflow of rivers, remain for about 5-15 days in most parts of the coastal belt, causing severe damage to crops and impacting food security of farm households (Mishra et al. 2010).

A national program supported by the government of India called 'National Food Security Mission' has been operating in Odisha since 2007 in order to enhance rice production. This program aims to increase production through area expansion and to sustainably increase productivity, with the objectives of restoring soil fertility and productivity at the farm household level. The Jajpur district in coastal Odisha is one of the most frequent and worst sufferers of flash floods. Agriculture is the primary occupation and sole source of food and income for the vast majority of the poorest farmers of the district. Paddy is the most important crop during the wet season, when it is at high risk of flash floods. To guard against losses from these, most farmers use older and traditional varieties, which can withstand flooding to some extent but produce lower yields (Ismail et al. 2013). In many cases farmers have abandoned rice cropping altogether and prefer to leave their fields fallow during the monsoon season. As a result of this problem, Jajpur was the first district in 2007-08 in which SS1 was introduced by the Central Rice Research Institute (CRRI), before its official release in 2009. Rice cultivation was subsequently re-introduced in some areas, where farmers had abandoned it in the wet season due to the recurrent occurrence of flash floods.

The present study was aimed at introducing Swarna-Sub1 (SS1) through cluster demonstrations in flood prone coastal Odisha in order to sustain rice cultivation during the wet season. This was followed by the integration of mung bean (Vigna radiata) in the dry season as a new cropping system. The main purpose of the intervention was to ensure food and economic security of the flood prone rice growing areas by shifting farmers from traditional rice varieties to flood tolerant ones (SS1 in the present case). The response of SS1 towards flash flooding and its impact on choice of crops grown by famers, choice of paddy varieties cultivated and number of plots under paddy cultivation was studied over the years 2013 and 2014. The yields obtained from traditional landraces and non-Sub1 HYVs were studied in comparison with the SS1. Impacts of SS1 in terms of yields from paddy fields and income for farmers was also duly appraised.

\section{Materials and methods}

\section{Site and duration of the study}

The Jajpur district of Odisha (India) is located at $20^{\circ} 33^{\prime}$ to $21^{\circ}$ $10^{\prime} \mathrm{N}$ latitude and $85^{\circ} 40^{\prime}$ to $86^{\circ} 44^{\prime} \mathrm{E}$ longitude, at an average elevation of $8.0 \mathrm{~m}$ above mean sea level. The district receives 
a normal annual rainfall of $1559.9 \mathrm{~mm}$, mostly during the wet season (July to October), leading to flash floods in the area. Bari is one among the blocks of Jajpur district prone to severe damage by flash floods and quite often rice paddy during the wet season remains inundated. Amathpur and Asalpur are among the many other villages in Jajpur (Fig. 1) where frequent floods have discouraged farmers from growing rice paddy in the wet season due to heavy crop losses, in addition to losses in inputs and other investments necessary for crop production. As a result, most farmers in these villages either grow traditional rice varieties or leave their fields fallow during the wet season. They then cultivate a dry season legume (urd bean, Vigna mungo) followed by a short duration pre-wet season rice having very low yields. In the present study, primary selection of farmers from two villages (Amathpur and Asalpur) was carried out and SS1 was introduced in the wet season of 2013, followed by mung bean (Vigna radiata) varieties LGG-460 and SML-688 (growth season 80-90 days) in the dry season. The seeds of SS1 were distributed among the farmers in the target area. The same farmers were also provided with seeds of the mung bean varieties. As the SS1 was introduced in 2013 as a one-year single season intervention, 2012 was selected as the baseline year. The year 2014 was designated as the follow up year and used to identify medium term impact of the intervention. The study compared the yield performance of different varieties under similar flooding intensity during a specific period of time. Yield performance was recorded by the crop cutting method from areas of $10 \mathrm{~m}^{2}$ (De Datta et al. 1978). Although, yield performance depends upon many factors, such as management practices, the study was conducted under the current practices followed by farmers. These factors were not controlled in the demonstration plots.

\section{Profile of the beneficiaries}

The results of this study are based on a survey of 355 farmers, located in the two Jajpur villages. These farmers were the immediate targeted beneficiaries of the program to introduce $\mathrm{SS} 1$ rice in the region. An overwhelming majority of the beneficiaries in the present study come from socio-economically disadvantaged backgrounds with over three quarters of the households being either Dalit (Scheduled Caste), Adivasi (Scheduled Tribe), or belonging to some other backward caste (OBC). While our survey did not record the household income, we recognized that fewer than half of the farmers surveyed resided in houses that can be classified as permanent constructions, indicating their poverty. Agriculture was the primary occupation of nearly $90 \%$ of the beneficiaries.

\section{Monitoring and data evaluation}

The SS1 demonstrations were monitored during the entire period of study. Mapping of the demonstration plots was accomplished using the Global Positioning System (GPS). Adoption of SS1 over the years of study was also monitored using the satellite based data. Indian Remote Sensing (IRS) satellite data was used to study the land use changes.

\section{Location of coastal districts and study villages in Odisha, India}

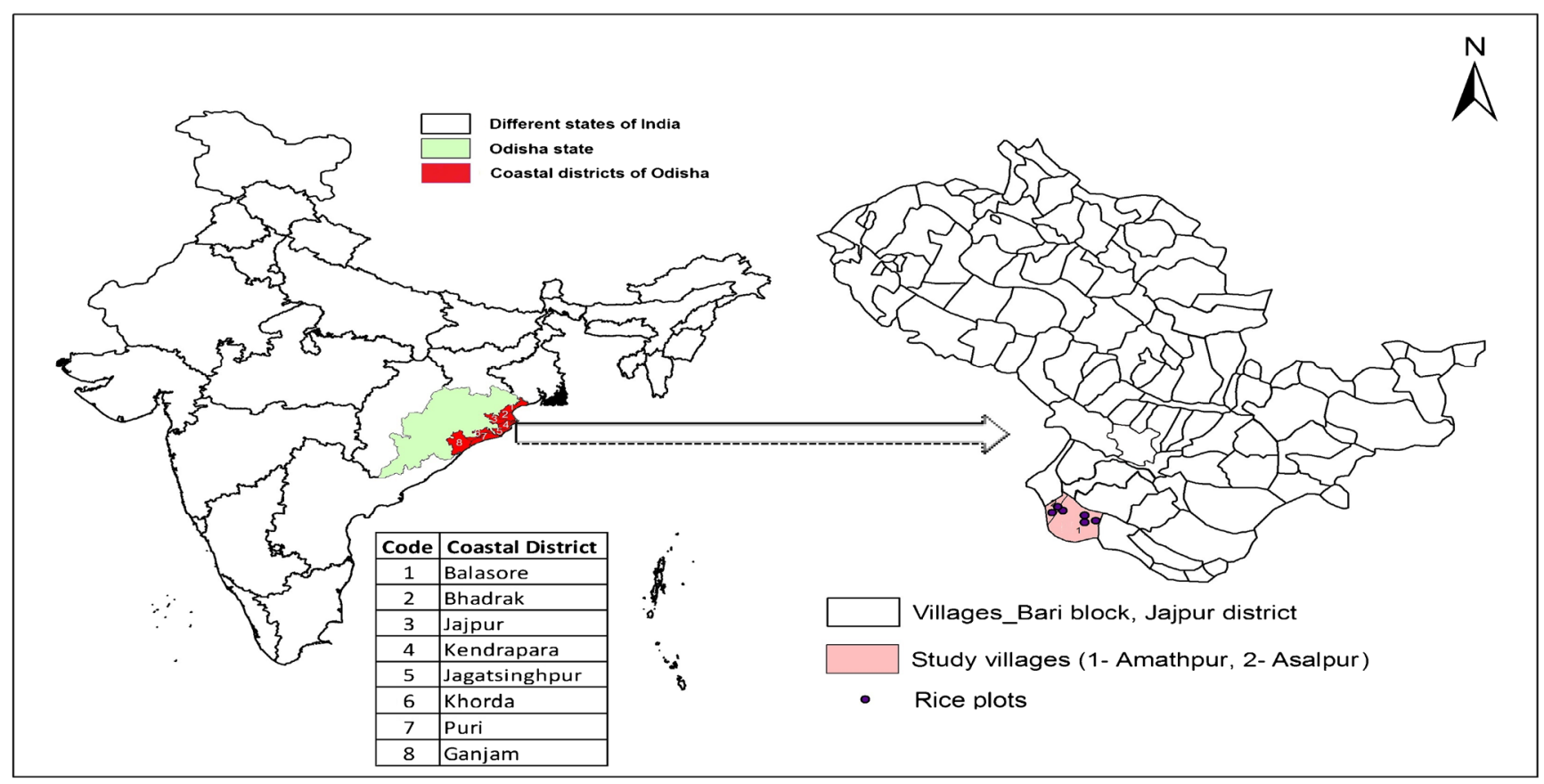

Fig. 1 Map showing coastal Odisha along with the villages and rice plots under study 
Likewise, the occurrence, duration and intensity of floods were also recorded.

Data regarding choice of the crops, plot yields and household output (along with sales) over all 3 years was retroactively obtained during the household surveys in early 2015. Evaluation of data was carried out with the help of SPSS (Statistical Package for Social Sciences) software (version 16.0). A rigorous empirical analysis was also carried out to identify the actual output and yield premiums derived from SS1. A fixed effect regression model, similar to that described by Dar et al. (2013) was adopted in order to estimate the output and yield gains from SS1.

\section{Conceptual framework}

Among various abiotic stresses, flooding is a constraint for rice production in years and areas of high rainfall. Although rice is well known for its cultivation in flooded soils, most cultivars cannot survive submergence for more than a week (Adkins et al. 1990). Flash floods leading to complete submergence of plants for up to two weeks is a major recurring problem for rice production in rainfed lowland areas (Septiningsih et al. 2009). Coastal Odisha is one of the most flood prone areas of India where paddy cultivation is the main source of livelihood for most farmers. Farmers usually cultivate rice during the wet season and save part of the harvest for household consumption. The rest is sold to generate income for other household requirements. Devastation of the paddy crop by flash floods impairs the food and economic security of the farmers and ultimately their survival. Moreover, most of the farmers residing in areas prone to submergence belong to the socially and economically under privileged sections of society. Thus, flooding affects the poorest farmers disproportionately, causing them to reduce their consumption, withdraw their children from school, sell assets to meet immediate needs and, in extremis, to migrate in order to find employment (Dar et al. 2013). Furthermore, farmers growing rice in stress prone environments are well aware of the risks involved and are thus reluctant to use expensive agricultural inputs, thereby leading to further reduction in yield potential in these regions (Courtois et al. 2000).

To safeguard against submergence, some farmers cultivate older and traditional varieties which can withstand flooding to some extent, but these land races produce very low yields (Ismail et al. 2013). In many cases, farmers have abandoned rice cropping altogether, preferring to leave their fields fallow during the wet season. Rice varieties possessing flood tolerance along with high yield and desirable grain quality is the most coherent approach to coping with the menace of submergence (Singh et al. 2013). These varieties are the most promising and deliverable technology for ensuring food and economic security in the communities dependent on rainfed rice (Ismail et al. 2013). Thus, the present study was aimed at introducing SS1, a submergence tolerant rice variety, in order to ensure food and economic security in the flood prone areas of coastal Odisha. SS1 can withstand submergence for up to 2 weeks and has high yield potential and better grain quality than the local landraces. Thus, this variety has the potential to ensure food and economic security in these flood prone areas.

\section{Results and discussion}

The rice crop was well established before the incidence of heavy rains in September 2013, which caused rivers to overflow, inundating paddy fields in many villages including the two villages selected for the demonstration of SS1. The crop remained submerged for 10-16 days depending upon the elevation of the land. Due to the Phailin cyclone in October 2013, the crop was again submerged for a few days. SS1 started to recover immediately after the water receded and was left relatively unimpaired. It was only after 13 years, many farmers from these villages have harvested a bounty crop of paddy in the wet season. Yield of SS1 was relatively high when the submergence period was less than 10 days and was still about $2.5 \mathrm{t} \mathrm{ha}^{-1}$ even after the two weeks' submergence (Fig. 2). These observations are in accordance with the published data of agronomic trials conducted in experimental stations and farmers' fields during 2008-2011 (Ismail et al. 2013). SS1 has withstood submergence for up to 17 days in research trials (Singh et al. 2009; Sarkar et al. 2009).

\section{Choice of crops}

Farmers have overwhelmingly preferred to cultivate rice paddy in the wet season and legumes like blackgram (urd bean, Vigna mungo) and greengram (Vigna radiata) in the dry season during the three years of the study. The percentage of plots under rice cultivation during the wet season of 2012 was 70\%, rising to $90 \%$ and $86 \%$ in 2013 and 2014, respectively (Fig. 3). This increase was primarily due to fallow plots being brought into paddy cultivation. Out of 1351 available plots, 394 were left fallow in the wet season of 2012 and from these 275 (about $70 \%$ ) were cultivated with paddy during the wet season of 2013. Overwhelmingly, $96 \%$ of the paddy in these plots was planted with SS1. During 2014, 229 out of these 275 plots were re-cultivated with SS1, indicating a readoption rate of about $83 \%$. It can be inferred from the data that plots left fallow in the wet season of 2012 were probably situated on lower lands with poor drainage, making them highly susceptible to both flooding and prolonged submergence. The introduction of flood tolerant SS1 permitted cultivation on these plots, expanding the local agricultural area. Choice of crops by farmers during the dry season was very consistent, with about $70 \%$ being allocated to legumes over all 3 years. The remainder of the plots were mostly left fallow and there was no paddy cultivation during the dry season. 
Fig. 2 Yield of Swarna-Sub1 as affected by different durations of submergence during the wet season of 2013

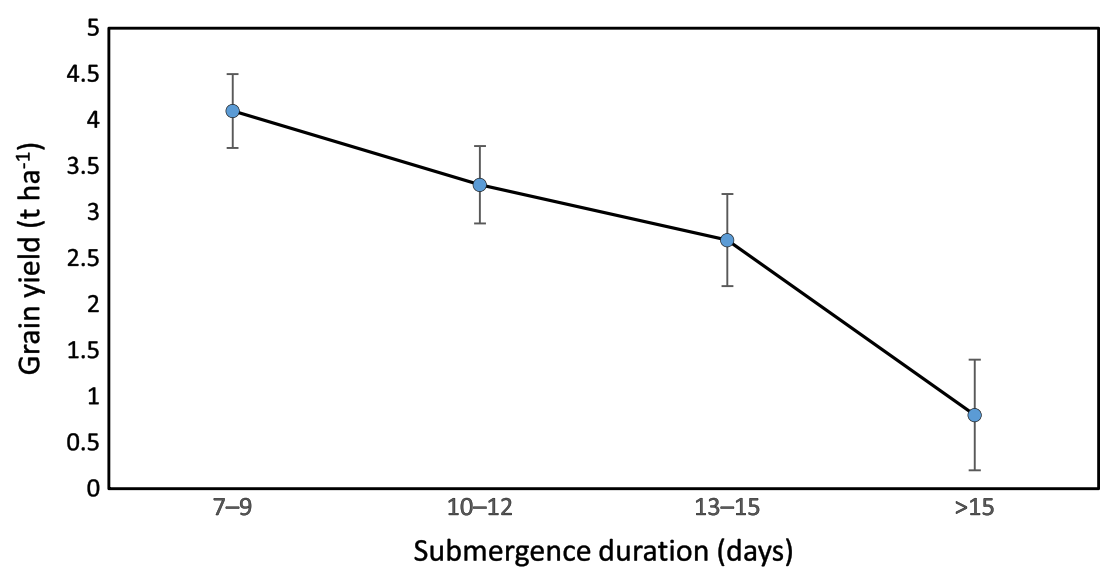

In the wet season of 2012, just fewer than half the farmers cultivated their plots with traditional varieties (Fig. 4). About a quarter opted for high yielding varieties (HYVs), such as Puja and Swarna. None of the beneficiaries had access to SS1 seed during this season. During the wet seasons of 2013 and 2014, the majority of the farmers switched to SS1. In the wet season of 2013 , over $80 \%$ of the plots were cultivated with SS1. However, the number was reduced to about $65 \%$ in the wet season of 2014. The reduction in the number of plots cultivated with SS1 in 2014 as compared to the previous year was somewhat anticipated. In 2013, the beneficiaries received the SS1 seeds free of cost along with other inputs and were then more willing to grow it on the major portion of their holdings. In the next year, however, when the seeds were no longer freely available, farmers had to make a choice either to purchase the seeds or use seeds retained from the previous year, or fall back on the traditional varieties with which they were quite familiar. Moreover, although the price of SS1 seed is almost the same as that of traditional and other HYVs, farmers who had not saved seed from the previous year's SS1 produce might have been reluctant to purchase new seed from market. Furthermore, two-thirds of the plots on which SS1 was discontinued during the wet season of 2014 recorded no output in 2013. These plots were probably unsuitable for SS1 cultivation, due to their low elevation and severe flooding. This is further supported by the fact that on nearly three quarters of these plots, no output was obtained during the wet season of 2012. The other contending explanation could be that the heavy and prolonged submergence that occurred in the aftermath of the Phailin cyclone in 2013 destroyed the paddy crop, resulting in loss of confidence in SS1, causing farmers to switch back to their traditional varieties. We argue this from the observation that average yields of about $2.75 \mathrm{tha}^{-1}$ were obtained during the wet season of 2013 on the plots where SS1 was continued in the wet season of 2014. This is about $15 \%$ more than the overall average yield $\left(2.45 \mathrm{tha}^{-1}\right)$ during the wet season of 2013. An average yield of $1.87 \mathrm{tha}^{-1}$ was obtained during the wet season of 2013 on plots where SS1 was grown, but was replaced by traditional varieties in 2014.

The majority of the farmers preferred to persist with SS1 in 2014, indicating that they found this variety more profitable than the landraces and HYVs: 345 out of the 355 farmers interviewed cultivated SS1 in the wet season of 2013 and about $75 \%$ of them persisted with SS1 in 2014. This trend is similar to the percentage of plots on which SS1 was continued in the wet season of 2014 . Out of the remaining $25 \%$ of plots on which SS1 was discontinued in 2014, a quarter were left fallow and about a third were sown with traditional varieties. The remainder were sown with HYVs other than SS1. Many farmers preferred to cultivate low yielding traditional varieties
Fig. 3 Choice of crop cultivation during the wet seasons of 2012 2014

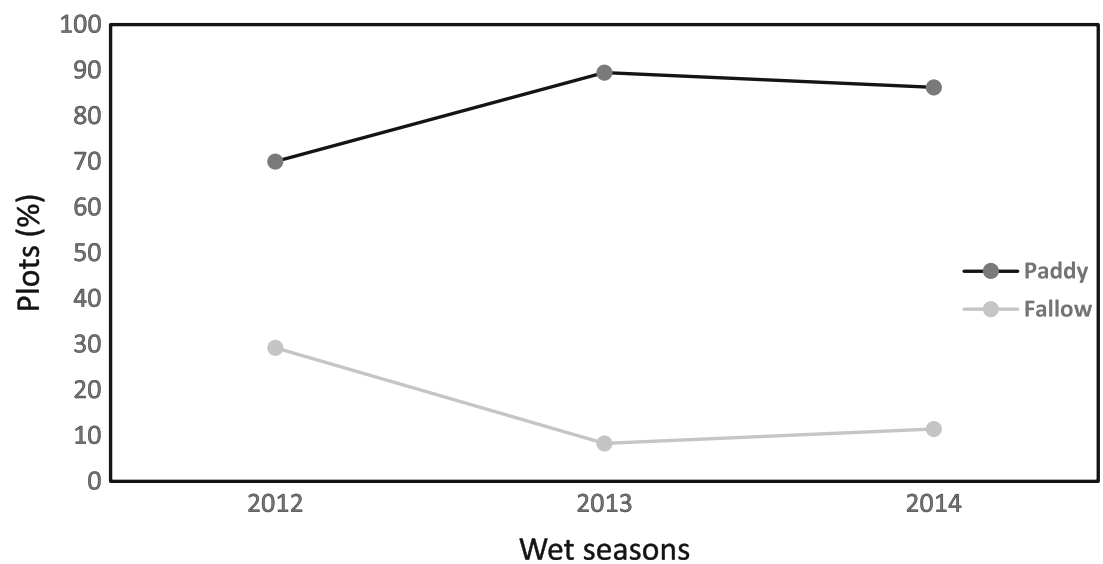


Fig. 4 Choice of paddy varieties during the wet seasons of 201214

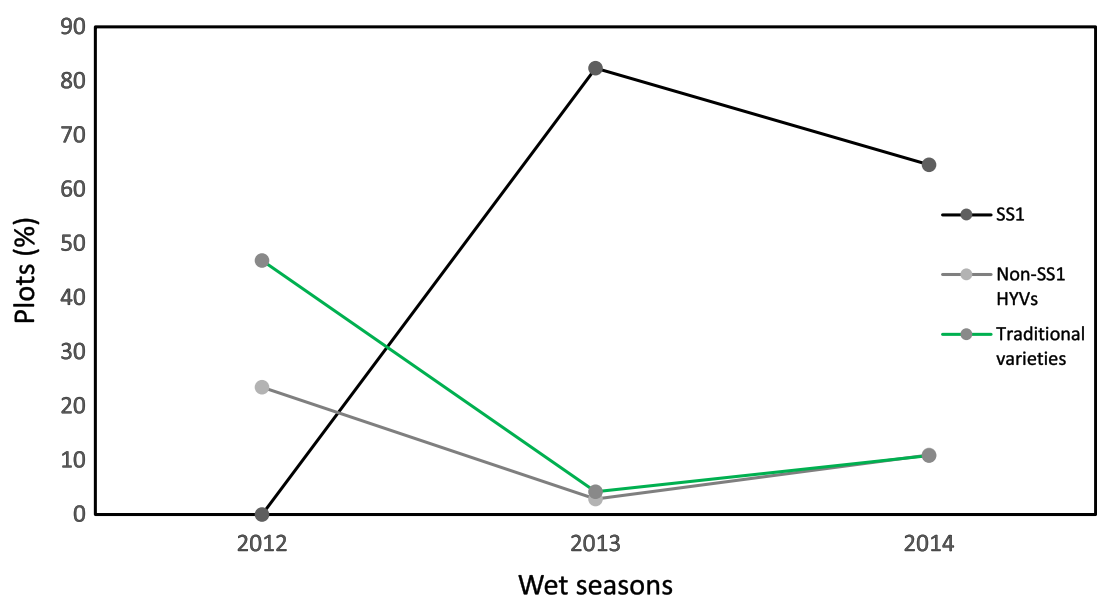

over HYVs owing to their flood tolerance. The direct substitution of traditional varieties with SS1 has the potential to double the rice yields not only in flooding years, but also in years when there is no flooding. This is supported by the results of Emerick et al. (2016) who observed the shift from traditional varieties to SS1.

The Indian Remote Sensing Satellite (IRS) L3 images of Amathpur, Asalpur and adjoining villages situated on the bank of the Birupa river in the Jajpur district of Odisha are presented in Fig. 5. The images reveal the changes in cropping patterns during 2012-2014 due to introduction of SS1 in the area. The vegetation on these False Colour Composite images is red, rivers and flooded/waterlogged areas are in blue to green, whereas fallow areas are in grey-green. Village habitation surrounded by trees appears in bright red. Image (A) shows blackgram (BG) crop at the vegetative stage in these villages during the wet season of 2012. In 2013, cluster demonstrations of SS1 were conducted in a 24 ha area shown by a black outline on image (B). Due to the Phailin cyclone in October 2013, severe flooding occurred, the effect of which can be seen by the bluish colour in the eastern part of the demonstration site. Despite severe flooding, the success of SS1 in 2013 encouraged farmers of the two villages to grow rice on a larger area during the wet season of 2014. Image (C) shows that SS1 cultivation was extended by 35 ha as indicated by the yellow outline on the image. These images show that farmers used to keep their fields fallow during the wet season through 2012 and cultivate blackgram in the dry season. Rice cultivation on these fields was introduced in 2013 when SS1 become available.

\section{Plot yields}

There has been a steady and significant increase in paddy yields per unit area between 2012 and 2014. During the wet season of 2012, average plot yields for paddy was about $1.3 \mathrm{t}$ $\mathrm{ha}^{-1}$, almost doubling to $2.5 \mathrm{t} \mathrm{ha}^{-1}$ in the wet season of 2013, which was further doubled to around $5 \mathrm{t} \mathrm{ha}^{-1}$ during the wet season of 2014. This nearly four-fold increase in average yields of plots is attributed to the introduction of SS1. The last figure is consistent with the yields obtained in controlled field experiments with SS1 (Singh et al. 2016). The lower yields in the wet season of 2013 is primarily due to the devastation caused by severe flooding caused by cyclone Phailin, which hit the eastern coast of India in October 2013.

Yields obtained from traditional landraces and non-sub1 HYVs were comparable, and were substantially lower than those of SS1. During the wet season of 2012, the average yield of traditional landraces was around $1.3 \mathrm{t} \mathrm{ha}^{-1}$ and non-sub1 HYVs was about $1.5 \mathrm{t} \mathrm{ha}^{-1}$. This trend was exactly reversed in 2013. The yield enhancement in traditional varieties during 2013 is attributed to the occurrence of severe floods in the aftermath of the Phailin cyclone. Under heavy flooding, local landraces generally produce higher yields than popular HYVs (such as Swarna and Puja) due to the high sensitivity of the modern cultivars towards submergence. In the wet season of 2014, the overall yields for both the types of varieties were much higher.

The yields obtained in the wet season from four major rice varieties (i.e., SS1, Swarna, Puja and Mugdi) were also compared (Fig. 6). Swarna and Puja are the two major HYVs which are commonly cultivated in this area, while Mugdi is the dominant landrace of the region. In the wet season of 2012, the average yield of Swarna was 50\% higher than Mugdi and 30\% higher than Puja. Puja yielded about $1.4 \mathrm{t}$ $\mathrm{ha}^{-1}$ in 2012, which is approximately $15 \%$ higher than that of Mugdi. In the wet season of 2013 with heavy flooding in October as a result of cyclone Phailin, Mugdi produced higher average yields than Swarna and Puja. While SS1 produced $2.5 \mathrm{t} \mathrm{ha}^{-1}$, Mugdi yielded about $1.7 \mathrm{t} \mathrm{ha}^{-1}$, which is $30 \%$ and $42 \%$ higher than that of Swarna and Puja, respectively. The lower yields of these two HYVs is due to their extreme sensitivity to flooding. Thus, in the absence of a reliable flood tolerant high yielding variety, such as SS1, farmers find it more beneficial to cultivate traditional varieties (such as Mugdi) in flood prone areas. Replacing traditional varieties with SS1 has the potential to double the yields in flood prone areas, irrespective of the occurrence of floods. In 2014, with relatively low flooding, 

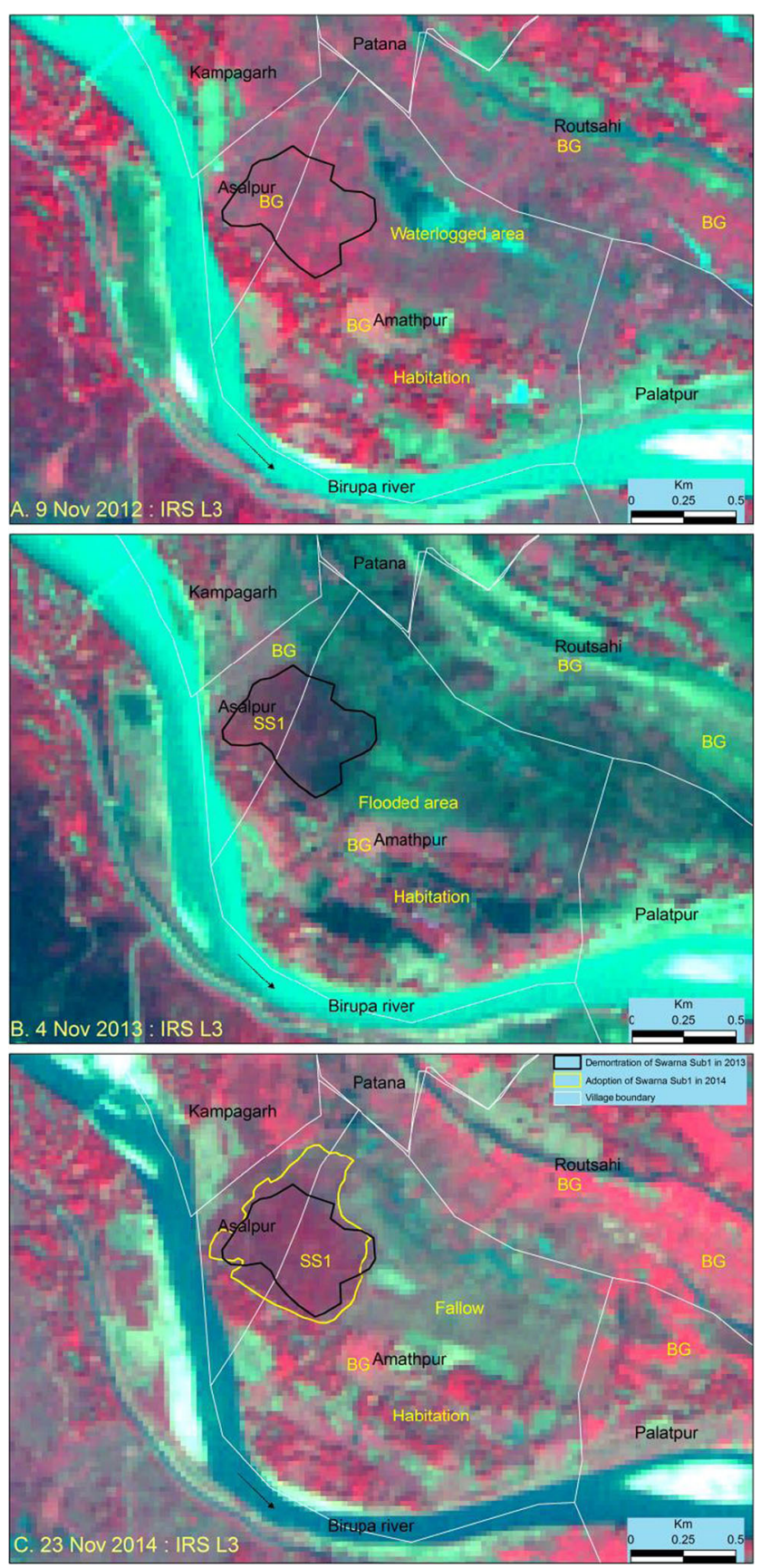

Fig. 5 IRS images of Amathpur, Asalpur and adjoining villages showing an expansion of area under Swarna-Sub1 during 2012-2014 (BG stands for blackgram, Vigna mungo). For full explanation see text

a trend similar to the wet season of 2012 was observed. Mugdi produced the lowest yield of about $1.9 \mathrm{tha}^{-1}$. This is less than half the yield of Swarna and about 3 times lower than the yield of SS1. Puja with a yield of more than $3 \mathrm{tha}^{-1}$ produced $60 \%$ higher yields than Mugdi. Swarna outperformed Puja by a similar margin. The reason for the low average yields during the wet season of 2012 is that virtually half the plots produced no yield during this period, probably due to being at extremely low elevation and therefore ill-suited to HYVs combined with the low use of inputs and poor management practices.
The present study compared the performance of different varieties under similar flooding intensity during a specific period of time. The data for one year before and after the intervention was evaluated for better comparison of varietal dynamics. Although, no floods were observed in either 2012 or 2014, floods of a similar magnitude to those of 2013 occurred in the sample area during 5 of the previous 10 years. As demonstrated in the present investigation and reported by previous studies (Mackill et al. 2012; Ismail et al. 2013), SS1 shows substantial yield advantages during both flooding and non-flooding years. Swarna is being cultivated over a large area and can be safely replaced by SS1 irrespective of the occurrence of flooding, considering the fact that floods are becoming less predictable in time and space in the present scenario of climate change. However, the research findings by Lybbert and Bell (2010) suggest that the spread of submergence tolerant varieties can be rapid only if the exposure to flooding is more frequent.

\section{Household level output and sales}

Household sales serve as a proxy for the income of farmers from farming activities. A survey was carried out at the end of January 2015, by which time many households had not completed the sales of crops harvested in the preceding wet and/or dry season. To avoid any ambiguity arising from the incompleteness of data, analysis of sales and total household output was restricted to those households which had completed their sales by that time. This amounted to 82 households in the wet seasons and 71 in the dry seasons of all 3 years.

Average household income from paddy sales during the wet season of 2012 was about 3000 rupees, with the corresponding average household output of around 1.2 tons (Fig. 7). Despite the occurrence of flooding, sales were increased to over 11 thousand rupees (nearly four-fold) due to the doubling of paddy output to over 3 tons in 2013. Income from paddy sales in the wet season of 2014 was boosted still further to nearly 14 thousand rupees, with the average household paddy output of about 4 tons. The sharp hike in average household paddy output and sales is consistent with the increase in paddy yields per unit area. As the price of paddy remained almost the same at 10,000 rupees per ton of grain, the increase in sales was due to the increase in quantity sold as reported previously by Dar et al. (2013).

During dry seasons, the farmers incurred relatively higher income from crop sales. In the dry season of 2012, the average of 6000 rupees per household was realized from the sale of blackgram. This increased significantly to over 9000 rupees in the dry seasons of both 2013 and 2014. The hike in sales was primarily attributed to the willingness of farmers to sell a larger proportion of their produce. Farmers sold the $50 \%$ of their output in the dry season of 2012 and about $60 \%$ in subsequent years. Another reason for the increase is the introduction of new and high yielding varieties of mung bean. 
Fig. 6 Comparison of grain yields of Swarna-Sub1, Swarna, Puja and Mugdi. The yield data was recorded by the crop cutting method from $10 \mathrm{~m} \times 10 \mathrm{~m}$ areas. (* and ** indicate that the yield of SS1 is significantly higher than all the other 3 varieties during that year at the levels at $p=0.05$ and 0.01 , respectively)

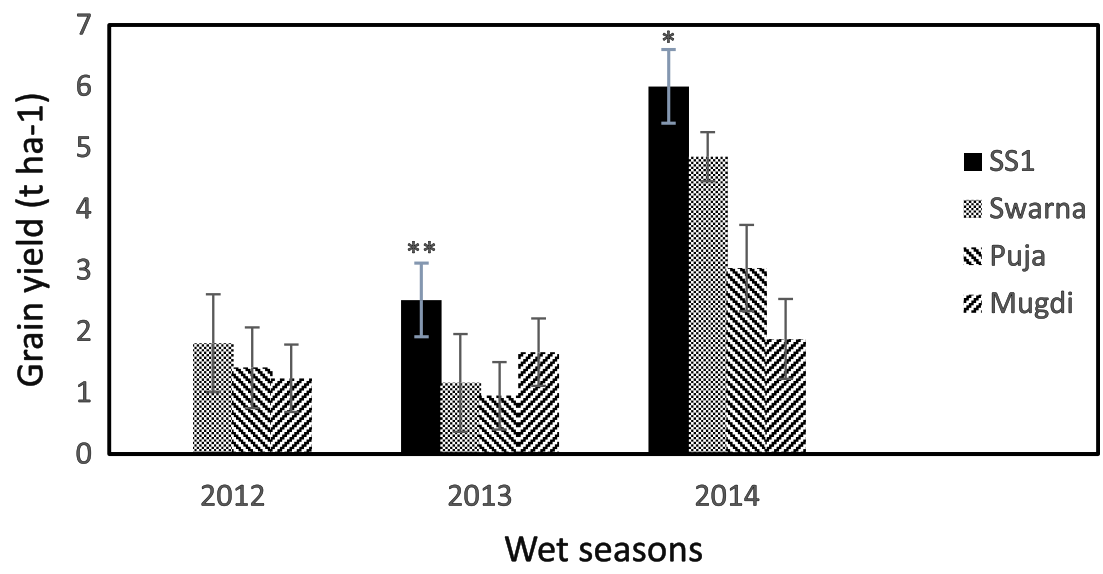

$\delta)$. This allows control of unobservable plot-characteristics, such as short-term fertility and the incidents common to all farmers in a specific season of a year, such as flooding due to heavy monsoon rains. Results are based on a comparison of output and yields of the same plots (within-plot) over years. ' $Y$ ' represents the plot output or plot yields.

The unit of observation in this case is farmer-plot-season-year. ' $S S$ ' is a categorical variable whose value is 1 if the plot is cultivated with SS1, otherwise it is 0 . ' $H Y V$ ' is another categorical variable, with the value of 1 if the plot is cultivated with a highyielding paddy variety (except SS1) and it 0 otherwise. Similarly, 'Gram', 'Fallow' and 'Other' are also categorical variables equaling 1 or 0 , depending upon if the plot is cultivated with blackgram, left fallow, or cultivated with any other crop (apart from paddy and blackgram). The category omitted here is the traditional variety which acts as benchmark for the comparison of results. The control parameters included whether the plot was irrigated (Irrigated), the area of the plot (PlotArea) and the total land (TotalLand) available to the farmer. The standard errors were clustered in each specification at the farmer level to allow for the potential correlation in the choices and decisions of farmers.
In the above equation, ' $i$ ' represents the plot, ' $j$ ' the farmer, ' $k$ ' the season and ' $t$ ' the year. Separate intercepts were specified for each farmer-plot and season-year combination ( $\alpha$ and

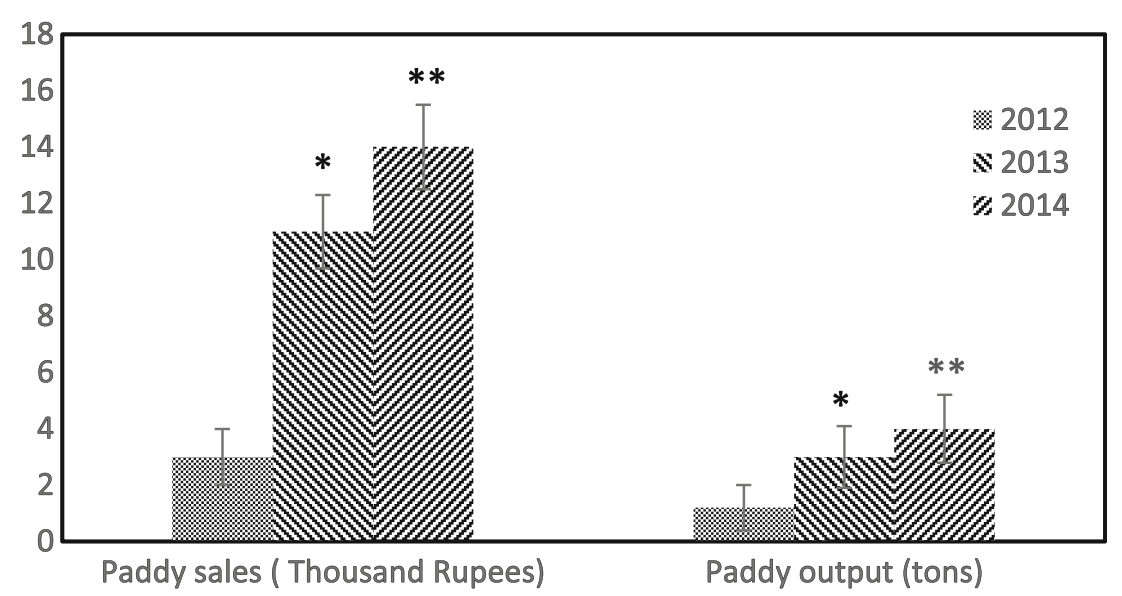

Fig. 7 Household paddy production and sales during the wet seasons of 2012-14. '*' indicates that the paddy sales during 2013 were significantly higher than that in 2012 at the level, $p=0.01$; ' $* *$ ' indicates that the paddy sales in 2014 were significantly higher than in other two years at the level, $p=0.01$; Similarly, '*' indicates that the paddy output during 2013 was significantly higher than that in 2012 at the level, $p=0.01$; ' $* *$ ' indicates that the paddy output in 2014 was significantly higher than in other two years at the level, $p=0.01$ ) 
The primary coefficients of interest are $\beta_{1}$ and $\beta_{2}$, which estimate the benefit (or loss) in output (yields) after switching from traditional to high yielding varieties (SS1 or non-SS1). As the distribution of seeds to recipients was carried out on a nonrandom basis, we cannot attribute a causal interpretation to $\beta_{1}$ or $\beta_{2}$. Thus, our estimates are correlational, identifying the additional output or yields obtained in cultivating SS1 (or any other HYV) in lieu of the traditional varieties. This is conditional on the farmer-plot and season-year fixed effects and other controls included in the specification. The causal interpretation of the coefficients need to impose the additional assumption on the econometric model that there is no other unobserved factor correlated with the introduction of SS1 and also with the observed plot-level yields and output. Thus, if training pertaining to management practices is provided to farmers in addition to the introduction of SS1, it would possibly bias the coefficient on SS1 upwards, and the true causal impact of SS1 introduction on plotlevel output and yield per unit area would not be estimated.

The results revealed that the plots cultivated with SS1 offers nearly 0.25 tons of rice extra over those cultivated with traditional varieties (Table 1). Similarly, plots cultivated with non-SS1 HYVs furnish 0.20 tons of additional output compared to the traditional varieties. Both the values are highly significant. In comparison with traditional varieties, an additional $0.83 \mathrm{t} \mathrm{ha}^{-1}$ of output is obtained from the cultivation of SS1. Likewise, the non-SS1 HYVs produce about $0.65 \mathrm{t} \mathrm{ha}^{-1}$ over the traditional varieties. Both the values are again highly significant. The equality of coefficients for SS1 and other HYVs for either plot output or yield per unit area cannot be rejected. This implies that after conditioning on our set of controls and controlling the plot characteristics, seasonal weather fluctuations, farmer attributes and other timeinvariant factors, SS1 and non-SS1 HYVs are indistinguishable in terms of plot-output and yield per unit area. Therefore, the yield premium of SS1 over other HYVs is observed only during flooding years. This affirms the previous findings regarding SS1, particularly when compared with the HYV Swarna (Mackill et al. 2012; Ismail et al. 2013; Singh et al. 2013).

The regression results are in broad agreement with the descriptive statistics, particularly with regard to the plot level output and yield per unit area of SS1. However, unlike the descriptive trends where plot output and yields per unit area for traditional varieties and non-SS1 HYVs were comparable, the regression results revealed that the latter significantly outperform the former. This could be due to the fact that a number of factors are controlled in this specification such as plot-level fertility and seasonal weather fluctuations, which were not considered in the descriptive statistics. Commuting the regression coefficients into monetary values with the assumption that a kilogram of rice is priced at 10 rupees, it can be estimated that cultivating one hectare (ha) area can accrue an additional benefit of over 8000 rupees to a farmer if he switched from a traditional variety to SS1. The additional monetary gain from cultivating a non-SS1 HYV relative to a traditional variety is approximately 6000 rupees per hectare.
Table 1 Impact of the introduction of SS1 on plot wise output and yield per unit area

\begin{tabular}{lcc}
\hline & \multicolumn{2}{c}{ Dependent variable: Plot yields } \\
\cline { 2 - 3 } & Output (Tons) & $\begin{array}{l}\text { Yield (Tons/ha) } \\
(1)\end{array}$ \\
\hline SS1 & $0.25^{* * *}$ & $0.83^{* *}$ \\
& {$[0.10]$} & {$[0.33]$} \\
Non-SS1 HYVs & $0.20^{* * *}$ & $0.65 * * *$ \\
Legumes & {$[0.05]$} & {$[0.16]$} \\
& $-0.31 * * *$ & $-1.13 * * *$ \\
Other Crops & {$[0.04]$} & {$[0.11]$} \\
& $-0.40 * * *$ & -0.59 \\
Fallow & {$[0.11]$} & {$[0.40]$} \\
& $-0.36 * * *$ & $-1.20 * * *$ \\
Mean of dependant variable & {$[0.05]$} & {$[0.16]$} \\
Number of observations & 0.17 & 0.60 \\
Adjusted R-square & 13,319 & 13,319 \\
\hline
\end{tabular}

Unit of analysis in all the regressions is farmer-plot-year-season. All regressions include farmer-plot and season-year fixed effects, controlling for timeinvariant unobservable plot characteristics, seasonal features in each year (common across all farmers). Regressions also controlled for the area of each plot, total land available to the farmer and whether the plot was irrigated. Robust standard errors clustered at the farmer level are presented in parentheses. Significance levels: $* * * p<0.01 ; * * p<0.05 ; * p<0.1$

The monetary benefits accruing to farmers from switching over to SS1 is substantiated by the follow-up survey of bank deposits in two villages, covering 230 of the 355 beneficiary farmers. The average number of bank deposits per year was significantly boosted from about 2 in 2012 to nearly 4 in 2014 . As $90 \%$ of the households depend on agriculture as their primary occupation, the increased number of bank deposits can be attributed to higher agricultural incomes resulting from the introduction of SS1. This was complemented by the increased willingness of farmers to sell a larger proportion of their produce. Some more suggestive evidence regarding the positive impacts of switching over to SS1 is discerned through the trends in loan-taking of these 230 households. In 2012, the average loans taken by the households was about 7000 rupees, rising by about $5 \%$ in 2013, and subsequently by over $25 \%$ to about 9000 rupees in 2014 . This can be explained by the improvement in repayment abilities of the farmers in view of their increased agricultural income. As reported by the households, almost all the loans were borrowed for agricultural purposes and the introduction of SS1 can be linked to the additional use of fertilizers, increase in area cultivated, additional hiring of labor and improvements in agricultural technology. All of these have positive impacts on crop yields, thereby strengthening the rural economy. 


\section{Conclusion}

It is evident that the adoption of SS1 significantly increases paddy yields over traditional varieties, even after controlling for irrigation, total holdings of farmers, the fertility of individual plots, farmer-level decisions and seasonal weather fluctuations. Although, the raw coefficients reveal that plot level output and yield per unit area of SS1 is around 25\% higher than other HYVs, this difference is not statistically significant, subject to the control for time-invariant factors (influencing yields) and weather shocks (common to all the farmers). Therefore, the output and yield premium of SS1 over other HYVs is significant only during the occurrence of floods. This is clearly demonstrated in the descriptive statistics with SS1 offering a yield advantage of about twice that of other popular HYVs (Puja and Swarna) and also over that of the local floodtolerant variety (Mugdi). The regression results, along with the descriptive evidence offer a rational argument for the promotion of SS1 in flood-prone areas. However, the variation in areas flooded suggests that the benefits of SS1 across the farming population is likely to be uneven. Within the flood prone villages, farmers belonging to scheduled castes have a greater number of plots that are exposed to prolonged floods. As described by Dar et al. (2013), they are therefore likely to benefit most from the introduction of SS1.

Acknowledgements The authors are highly grateful to the Department of Agriculture, Government of Odisha for their kind support, especially in terms of the information they furnished. We owe the deepest sense of thankfulness to Bill and Melinda Gates Foundation for the monetary endorsement they ensured through STRASA (Stress Tolerant Rice for Africa and South Asia) project.

\section{Compliance with ethical standards}

Conflict of interest The authors declare that they have no conflict of interest.

Open Access This article is distributed under the terms of the Creative Commons Attribution 4.0 International License (http:// creativecommons.org/licenses/by/4.0/), which permits unrestricted use, distribution, and reproduction in any medium, provided you give appropriate credit to the original author(s) and the source, provide a link to the Creative Commons license, and indicate if changes were made.

\section{References}

Adkins, S. W., Shiraishi, T., \& McComb, J. A. (1990), Submergence tolerance of rice- a new glasshouse method for the experimental submergence of plants. Physiologia Plantarum, 80, 642-646.
Bailey, S. J., Fukao, T., Ronald, P. C., Ismail, A. M., Heuer, S., \& Mackill, D. (2010). Submergence tolerant rice: SUB1's journey from landrace to modern cultivar. Rice, 3(2), 138-147.

Bhowmick, M. K., Dhara, M. C., Singh, S., Dar, M. H., \& Singh, U. S. (2014). Improved management options for submergence-tolerant (Sub1) rice genotype in flood-prone rainfed lowlands of West Bengal. American Journal of Plant Sciences, 5, 14-23.

Coumou, D., \& Rahmstorf, S. (2012). A decade of weather extremes. Nature Climate Change, 2(7), 491-496.

Courtois, B., McLaren, G., Sinha, P. K., Prasad, K., Yadav, R., \& Shen, L. (2000). Mapping QTL associated with drought avoidance in upland rice. Molecular Breeding, 6, 55-66.

Dar, M. H., de Janvry, A., Emerick, K., Raitzer, D., \& Sadoulet, E. (2013). Flood-tolerant rice reduces yield variability and raises expected yield, differentially benefitting socially disadvantaged groups. Scientific Reports, 3, 3315. doi:10.1038/srep03315.

Das, K. K., Panda, D., Sarkar, R. K., Reddy, J. N., \& Ismail, A. M. (2009). Submergence tolerance in relation to variable floodwater conditions in rice. Environmental and Experimental Botany, 66, 425-434.

Dawe, D., Pandey, S., \& Nelson, A. (2010). Emerging trends and spatial patterns of rice production. In S. Pandey, D. Byerlee, D. Dawe, A. Dobermann, S. Mohanty, S. Rozelle, \& B. Hardy (Eds.), Rice in the global economy: Strategic research and policy issues for food security (pp. 15-35). Los Banos, Philippines: International Rice Research Institute.

De Datta, S. K., Gomez, K. A., Herdt, R. W., \& Barker, R. (1978). A handbook on the methodology for and integrated experiment Survey on rice yield constraints. Los Banos, Philippines: International Rice Research Institute.

Emerick, K., de Janvry, A., Sadoulet, E., \& Dar, M. H. (2016). Technological innovation, downside risk and modernization of agriculture. American Economic Review, 106(6), 1537-1561.

Ismail, A. M., Singh, U. S., Singh, S., Dar, M. H., \& Mackill, D. J. (2013). The contribution of submergence-tolerant (Sub1) rice varieties to food security in flood-prone rainfed lowland areas in Asia. Field Crops Research, 152, 83-93.

Lybbert, T. J., \& Bell, A. (2010). Stochastic benefit streams, learning, and technology diffusion: Why drought tolerance is not the new Bt. AgBioforum, 13(1), 13-24.

Mackill, D. J., Ismail, A. M., Singh, U. S., Labios, R. V., \& Paris, T. R. (2012). Development and rapid adoption of submergence-tolerant (Sub1) rice varieties. Advances in Agronomy, 115, 303-356.

Mishra, A. K., Erickson, K., Harris, M., Hallahan, C., \& Uematsu, H. (2010). Determinants of farm household income diversification in the United States. Evidence from Farm-Level Data. Paper presented at Agricultural and Applied Economics Association Annual meeting, July 25-27, 2010, Denver, Colorado, USA.

Palada, M. C., \& Vergara, B. S. (1972). Environmental effects on the resistance of rice seedlings to complete submergence. Crop Science, 12, 209-212.

Sarkar, R. K., Panda, D., Reddy, J. N., Patnaik, S. S. C., Mackill, D. J., \& Ismail, A. M. (2009). Performance of submergence tolerant rice genotypes carrying the Sub1 QTL under stressed and non-stressed natural field conditions. Indian Journal of Agricultural Science, 79, 876-883.

Septiningsih, E. M., Pamplona, A. M., Sanchez, D. L., Neeraja, C. N., Vergara, G. V., Heuer, S., Ismail, A. M., \& Mackill, D. J. (2009). Development of submergence-tolerant rice cultivars: The Sub1 locus and beyond. Annals of Botany, 103, 151-160.

Singh, S., Mackill, D., \& Ismail, A. (2009). Responses of Sub1 rice introgression lines to submergence in the field: Yield and grain quality. Field Crops Research, 113, 12-23. 
Singh, U. S., Dar, M. H., Singh, S., Zaidi, N. W., Bari, M. A., Mackill, D. J., Collard, B. C. Y., Singh, V. N., Singh, J. P., Reddy, J. N., Singh, R. K., \& Ismail, A. M. (2013). Field performance, dissemination, impact and tracking of submergence tolerant (Sub1) rice varieties in South Asia. SABRAO Journal of Breeding and Genetics, 45(1), 112-131.

Singh, R., Singh, Y., et al. (2016). From QTL to variety-harnessing the benefits of QTLs for drought, flood and salt tolerance in mega rice varieties of India through a multi-institutional network. Plant Science, 242, 278-287.

Tester, M., \& Langridge, P. (2010). Breeding technologies to increase crop production in a changing world. Science, 327, 818-822.

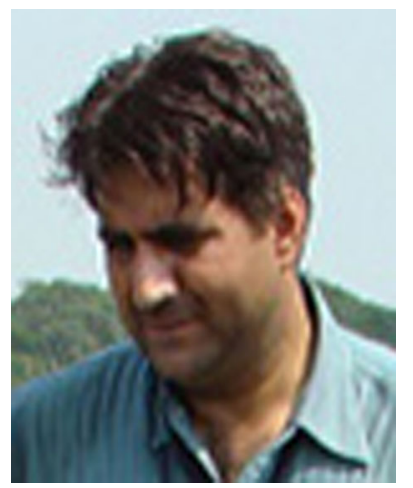

Dr. Manzoor H. Dar is a development specialist in agricultural research at IRRI-India with many years of experience working in South Asia. He has been actively involved in seed upscaling and dissemination of stress-tolerant rice varieties through the development of strategic partnerships in South Asia. He is well recognized for his extensive networking with national partners, including the Ministry of Agriculture, seed corporations, private seed companies, and reputable NGOs in India, Nepal, and Bangladesh. With an M.Sc. and Ph.D. in Plant Protection from Aligarh Muslim University (AMU), Dr. Manzoor is involved in leading innovative research and development activities in order to facilitate the delivery of technologies to end users and to accelerate the impact of stress-tolerant rice varieties in South Asia. Some of his work also focus on coordinating research on seed and extension activities and engaging in impact and adoption studies in stress-prone rainfed lowlands of South Asia.

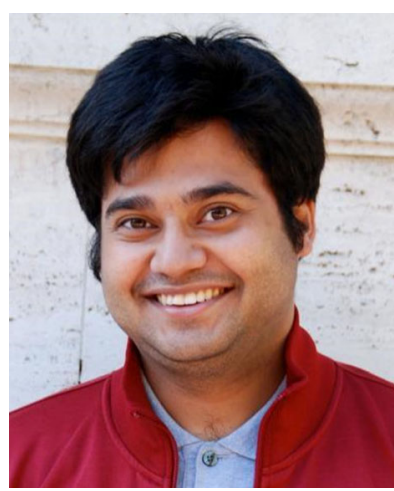

Mr. Ritadhi Chakravorty is pursuing a PhD in Agricultural \& Resource Economics, University of California, Berkeley. He has completed his M.S. in Agricultural and Resource Economics from the same Institute. His areas of specialisation involve Development Economics, Political Economy, Public Economics and Applied Microeconomics. Mr. Ritadhi is also working as a Graduate Student Instructor at International Economic Development Policy: Theory, Methods and Case Studies at UC Berkeley.

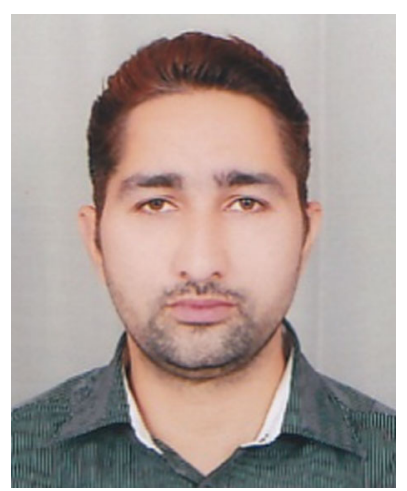

Dr. Showkat A. Waza is a specialist in various aspects of Plant Breeding, applying traditional as well as molecular biological approaches. After completion of his PhD (Genetics and Plant Breeding) from Banaras Hindu University, Dr. Showkat has been associated with teaching and research activities in the Department of Genetics and Plant Breeding (BHU). These have included marker assisted breeding for submergence tolerance into two popular varieties of rice. At IRRI, he is associated with the coordination, experiment implementation, evaluation, demonstration, monitoring and upscaling of various stress tolerant varieties of rice. Dr. Showkat has been awarded various laurels such as a UGC Research Fellowship, ICAR's Senior Research Fellowship (PGS), Best Doctoral Thesis Award, Young Scientist Award. He has more than 40 national and international publications to his credit.

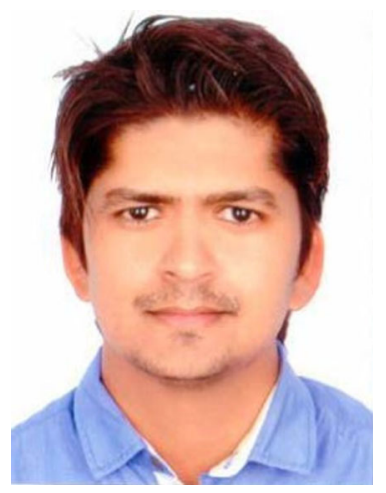

Mr. Mayank Sharma has a Masters Degree in Bioinformatics and joined IRRI in 2012. He is currently working as a specialist in Monitoring and Evaluation. His prime areas of duty involve implementation of a monitoring and evaluation framework, developing tools for this work and maintaining and updating monitoring and evaluation databases.

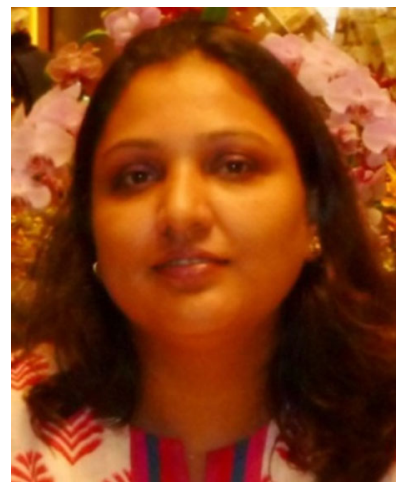

Dr. Najam W. Zaidi gained her M.Sc. (Ag.) in Plant Protection from Aligarh Muslim University in 1999 with Gold Medal and Ph.D. in Plant Pathology from G. B. Pant University of Agriculture \& Technology (GBPUAT), Pantnagar in 2004. She joined GBPUAT as Assistant Professor in 2005. Dr. Zaidi has developed several easily adoptable, economical and farmer-friendly technologies for mass multiplication and delivery of bio-control agents that have been widely accepted by farmers. Dr. Zaidi also has an Indian patent on one of these technologies to her credit. She had been associated with the development of two high yielding, high quality, blast resistant and salinity tolerant varieties, Kalanamak 3131 and 
Kalanamak 3119. She joined IRRI in June 2011, as a Post Doc Fellow under the Bill \& Melinda Gates Foundation funded "Stress-Tolerant Rice for Africa and South Asia (STRASA)" project and presently works as a Project Scientist with NARES in India, Bangladesh and Nepal to assess the susceptibility of stress tolerant rice varieties to different diseases and pests and particularly exploring the possibility of using microbes to enhance abiotic stress tolerance in rice. Dr. Zaidi has more than 60 publications to her credit, including over 35 research papers in journals of national and international repute, book chapters, reviews, manuals, popular articles and technical literature for farmers. She is a member of various Plant Pathology societies of India and also has many national and international accolades to her credit including the prestigious PP Singhal Memorial "Pesticide India Award- 2004" of the Indian Society of Mycology and Plant Pathology and "Most Promising Leader Award" from IRRI.

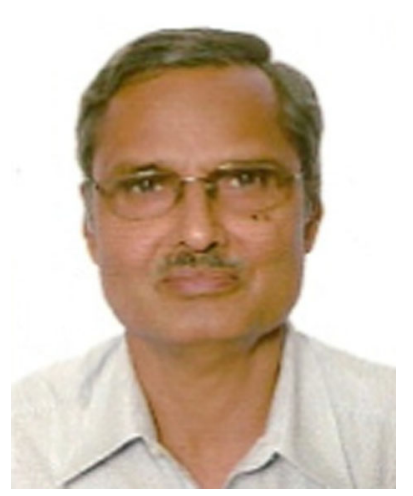

Dr. Amrendra N. Singh has been a Consultant at the International Rice Research Institute, working on characterization of abiotic stress-prone areas for targeted dissemination of stress-tolerant rice varieties in South Asia, using remote sensing and geographical information systems (GIS). He has 40 years experience in remote sensing and GIS applications to agriculture, wetlands, natural resources management, water resources, and sustainable development. He was Director of the Remote Sensing Applications Centre, Uttar Pradesh, India from 2001 to 2008 and has published more than 65 scientific papers in peer-reviewed journals and several book chapters.

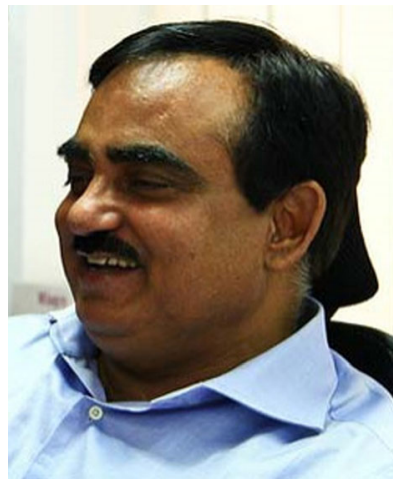

Dr. Umesh S. Singh is a plant pathologist, biotechnologist, and the South Asia Regional Coordinator of the Project Stress Tolerant Rice for Africa and South Asia (STRASA) funded by the Bill \& Melinda Gates Foundation. $\mathrm{He}$ is also the acting Country Representative for IRRI-India and IRRI-Nepal. In STRASA, Dr. Umesh is primarily responsible for the coordination of seed multiplication and dissemination of stress-tolerant rice varieties in stress prone environments in India Bangladesh and Nepal. He is also responsible for the development and facilitation of a network of partner organizations in these countries to implement the project. These monitor progress, track dissemination of the varieties, assess their impact, facilitate seed policy changes in national systems in order to speed up the process of varietal release and dissemination and help in capacity building. After the completion of his M.Sc. and Ph.D. in Plant Pathology from G.B. Pant University of Agriculture \& Technology, Pantnagar, Dr. Umesh held various positions in the university (GBPUAT) from 1983 to 2008 . He joined IRRI in 2008 and is known for the introduction of several innovations in his work, such as targeted dissemination of stress-tolerant rice varieties using GIS and remote sensing and tracking their diffusion through informal and formal seed sectors and ground surveys. His innovative approaches such as pre-release varietal seed multiplication and promotion and linking of varietal dissemination with mega developmental schemes of government and other organizations has helped the achievement of an unprecedented speed of seed multiplication and diffusion of stress-tolerant rice varieties in South Asia.

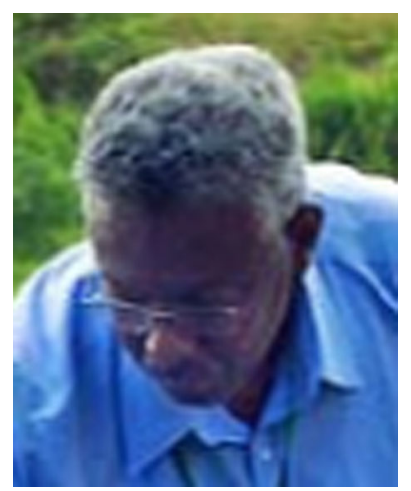

Dr. Abdelbagi M. Ismail is currently working on the tolerance of rice to abiotic stresses, including salinity and other soil problems (alkalinity, nutrient deficiencies, and toxicities) and complete and partial submergence during germination and early crop establishment. His work is focused on refining screening methods, identifying tolerant donors following large-scale screening, establishing genetic and physiological bases of tolerance, and assisting in developing tolerant breeding lines and their evaluation in the field. He has developed and validated sets of best management practices for different abiotic stress conditions to maximize expression of genetic tolerance and mitigate stress effects in farmers' fields. He is currently, Leader, STRASA (StressTolerant Rice for Africa and South Asia), IRRI, covering 21 countries, and a USAID-funded project in Nepal and Cambodia, leading the development and dissemination of abiotic stresstolerant rice varieties and strengthening of seed and seed systems and delivery. With a PhD in Botany from University of California, Riverside (1992), Dr. Abdelbagi has held various position in the university and has supervised about $35 \mathrm{PhD}$ and MSc students. He had been the Deputy Director General for Research, IRRI (interim, December 2015-March 2016). He is an editor of Annals of Botany-PLANTS, Plant Production Science, and Agricultural and Environmental Sciences Journal. He has also been Guest editor of special issues in Gene, Genomes and Genetics, Field Crops Research, and Rice. 